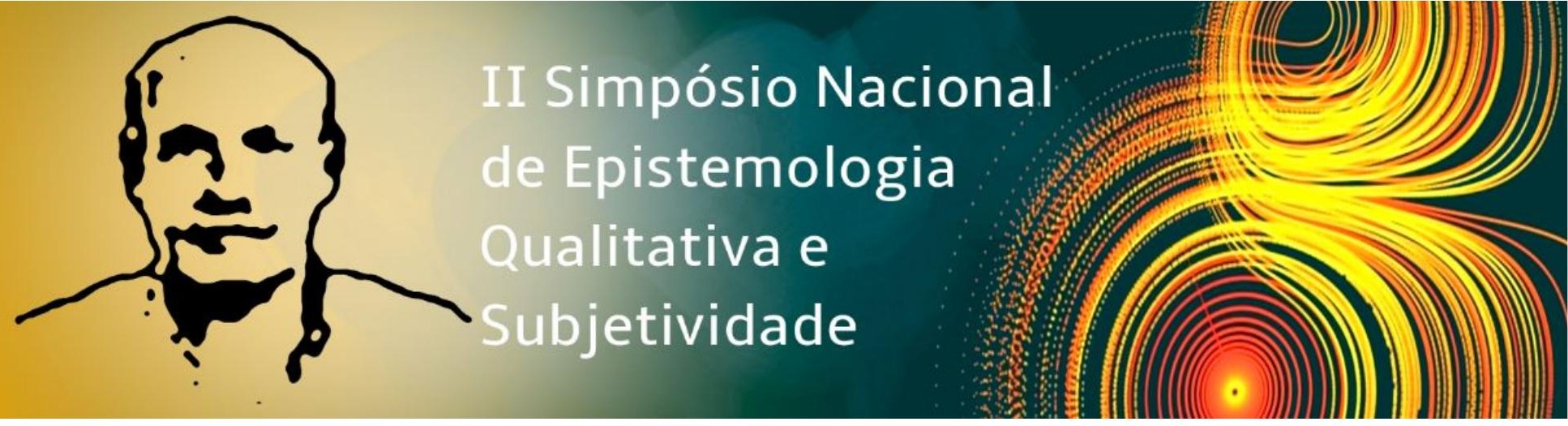

Eixo temático: A subjetividade na formação de professores e outros profissionais.

\title{
A SUBJETIVIDADE DOCENTE NA PRÁTICA PEDAGÓGICA DE UM PROFESSOR INICIANTE: UM ESTUDO DE CASO.
}

Prof. Me. Edjôfre Coelho de Oliveira, UECE edjofrecoelho@hotmail.com

Prof. Me. Saulo Vieira Cavalcante da Silva, UECE saulocmm@hotmail.com

Profa. Dra. Ana Ignez Belém Lima Nunes, UECE anaignezbelem@gmail.com

\section{Resumo:}

O presente trabalho aborda a questão dos aspectos subjetivos relacionados com a prática docente de um professor em início de carreira. Parte de uma pesquisa realizada com um professor iniciante com o objetivo de investigar o desenvolvimento profissional de professores em início de carreira no magistério. Propõe uma reflexão de que o impacto da formação de professores para a docência está relacionado com as questões subjetivas dos sujeitos envolvidos, sejam elas na sua dimensão social e individual. Para a realização do estudo, fizemos uso da Teoria da Subjetividade desenvolvida por González Rey (2006; 2009), e dos estudos acerca do processo de desenvolvimento profissional inicial trabalhados por Nono (2011), Tardif (2002; 1999) e Marcelo Garcia (1999). Os resultados apontam que há importância significativa dos anos de início na carreira docente em relação ao processos subjetivos de identidade profissional, embora exista a necessidade de investigação de estratégias e metodologias diversificadas para a pesquisa e promoção de processos de aprendizagem da docência.

Palavras chave: professor iniciante; subjetividade; formação docente. 


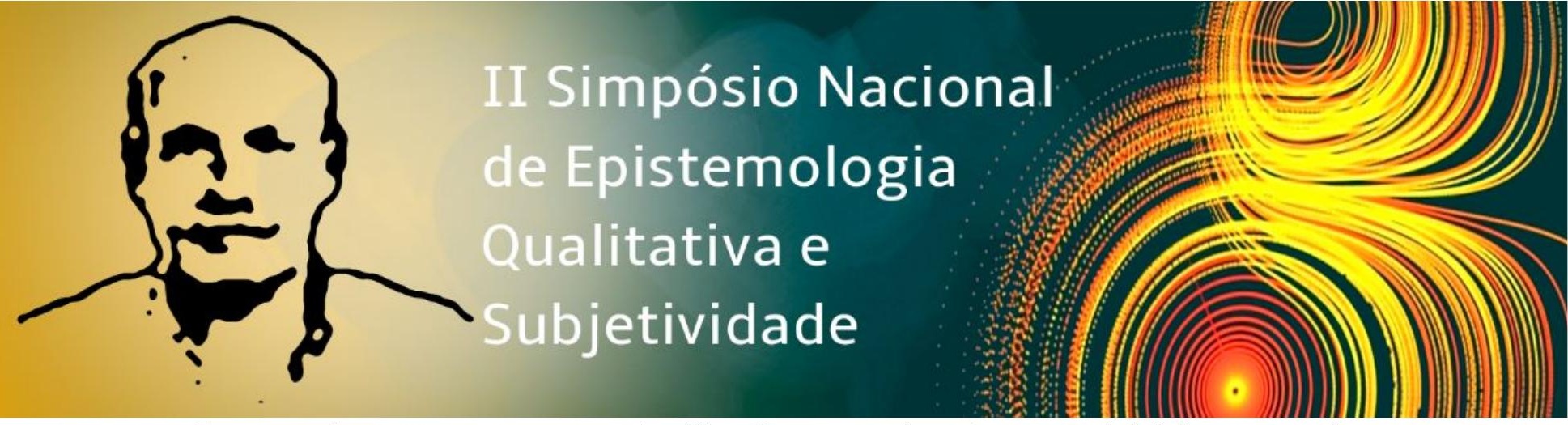

Este estudo aponta para uma significação expressiva dos anos iniciais na carreira docente em relação ao processos subjetivos de identidade profissional, assim como a necessidade de investigação de estratégias e metodologias diversificadas para a pesquisa e promoção de processos de aprendizagem da docência a fim de fortalecer a construção da identidade docente do professor em início de carreira no magistério.

\section{Considerações sobre a formação do professor iniciante}

O ingresso na carreira profissional geralmente causa muitas expectativas nas pessoas, não apenas porque significa uma conquista pessoal, mas sobretudo pelos desafios que a nova situação impõe.

Um dos precursores no desenvolvimento de investigações a esse respeito, o holandês Simon Veenman (1984), caracteriza essa fase de início de carreira como período de transição de estudante para professor e aponta justificativas para alguns sentimentos expressos por professores iniciantes. Assim, descreve como "choque com a realidade" a situação que atravessam muitos professores em seu primeiro ano de docência, ao perceber o distanciamento entre os ideais elaborados durante a formação inicial e a vida cotidiana de sala de aula.

$\mathrm{O}$ "choque com a realidade" tem origem no confronto entre o mundo interior dos professores e a realidade encontrada no meio socio profissional em que passam a estar inseridos, podendo provocar medos, frustrações e insegurança (apud BRAGA, 2001). É no início da carreira que o professor se depara com uma diversidade de problemas por ele desconhecidos, porque as possíveis soluções não constam no repertório de sua formação inicial ou nas habilidades originárias de outras fontes de construção do conhecimento, problema aqui compreendido como uma dificuldade que os professores iniciantes encontram para levar adiante a sua tarefa e que os impede de atingir os objetivos previstos (SIMON VEENMAN, 1984 apud BRAGA, 2001, p. 60).

Para esse autor, as causas para esse estado de "choque com a realidade" são de ordem pessoal e contextual. No primeiro caso, pode estar relacionada à eleição equivocada da profissão, atitudes e características pessoais inadequadas ou a uma formação inadequada muitas vezes, demasiado teórica e pouco prática. As causas contextuais dizem respeito a uma 


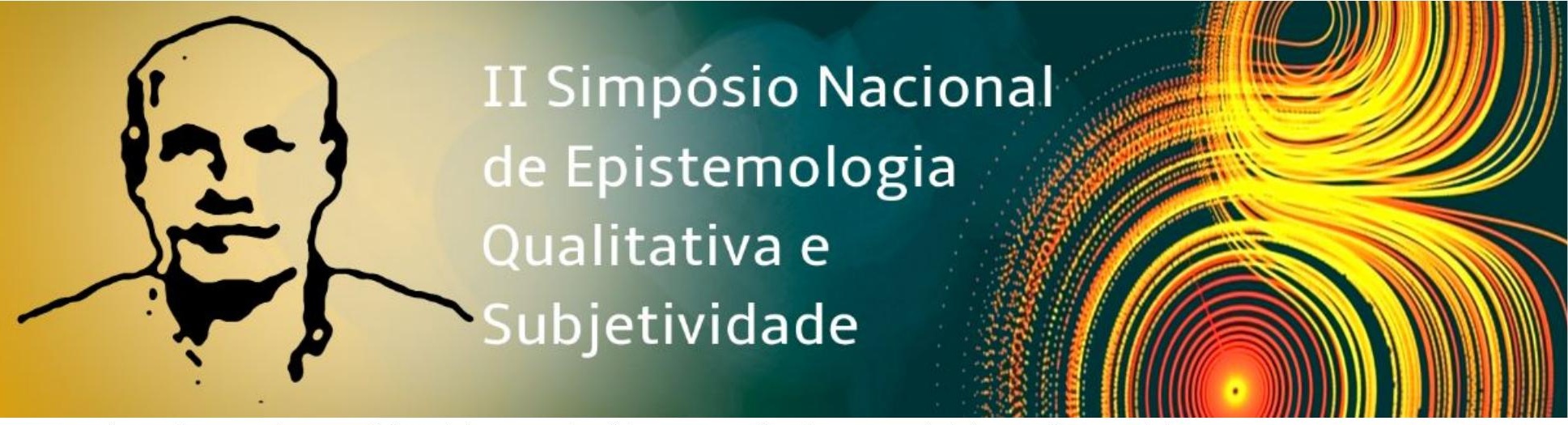

situação escolar problemática, traduzidas em relações autoritárias e burocráticas, estruturas organizativas rígidas, isolamento no local de trabalho, escassez de equipamentos, sobrecarga de trabalho, pressões dos pais, multiplicidade de funções e tarefas a desempenhar.

\footnotetext{
Na verdade, o choque com o real se refere à assimilação de uma realidade complexa que se apresenta incessantemente diante do novo professor, todos os dias que Deus dá. Essa realidade deve ser constantemente dominada, particularmente no momento em que se está começando a assumir suas funções no ensino (VEENAMN, 1984 apud BRAGA, 2001, p.79).
}

Para Huberman (1993, apud NONO, 2011, p. 16-17) haveria, então, duas fases durante os primeiros anos de carreira docente: uma fase de exploração (de um a três anos), na qual o professor escolhe provisoriamente a sua profissão, inicia-se por meio de tentativas e erros, sente a necessidade de ser aceito por seu círculo profissional (alunos, colegas, diretores, pais de alunos etc.) e experimenta diferentes papeis; a segunda seria a fase de estabilização e de consolidação (de três a sete anos), em que o professor investe a longo prazo na sua profissão e os outros membros da instituição reconhecem as suas capacidades. Além disso, essa fase se caracteriza por uma confiança maior do professor em si mesmo e pelo domínio dos diversos aspectos do trabalho, principalmente os pedagógicos.

De modo geral, é um período marcado pela desilusão e pelo desencanto e que corresponde à transição da vida de estudante para a vida mais exigente do trabalho. Os primeiros anos de profissão são decisivos na estruturação da prática profissional e podem ocasionar o estabelecimento de rotinas e certezas cristalizadas sobre a atividade de ensino que acompanharão o professor ao longo de sua carreira (NONO, 2011).

\section{A subjetividade docente}

Entendemos a identidade profissional do educador como algo contínuo, em construção. $\mathrm{Na}$ formação da identidade docente devemos considerar a subjetividade do educador, pois a singularidade é a marca dessa constituição. Em outras palavras, a modalidade subjetiva do professor está na base da formação da sua identidade docente. Nesse sentido, estamos num percurso de possibilidades, e não de certezas e definições acerca dessa identidade. Para tanto, 


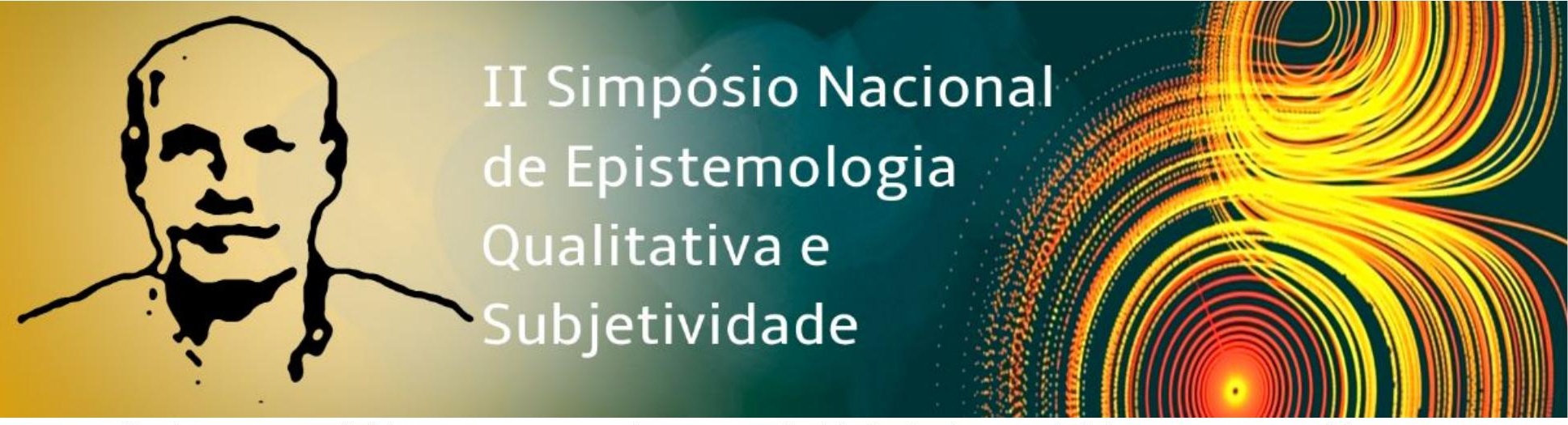

reflexivo que possibilita, entre outras coisas, a proximidade do docente iniciante com o sentido do "ser" docente.

González Rey (2009) investiu no desenvolvimento da categoria sentido, iniciada na obra de Vygotsky (1984), que lhe atribuiu um caráter integrador, ou seja, trata-se de um sistema dinâmico, envolvendo o pensamento, a conduta e a atividade concreta da personalidade. Para o autor, os sentidos estão carregados de emocionalidade; para expressar essa força, utiliza o termo subjetivo. O sentido subjetivo possui estreita relação com a afetividade, com os motivos, a imaginação, a criatividade, que integram os aspectos da subjetividade social e individual.

A subjetividade social e a subjetividade individual são duas categorias implicadas entre si, produzidas nas experiências de vida das pessoas e se manifestam nas contradições entre as necessidades sociais e particulares dos sujeitos, que constituem o sentido subjetivo. A primeira resulta dos processos de significação e de sentido, constituindo-se nos cenários da vida, delimitando e sustentando os espaços sociais em que vivem os indivíduos. A segunda representa os processos e as formas de organização subjetiva dos indivíduos. Ela sintetiza a história única de cada um, que se constitui por meios das relações sociais (GONZÁLEZ REY, 2009).

\section{Aspectos metodológicos}

Para a produção dos dados deste trabalho de estudo de caso, fizemos uso da entrevista reflexiva com um professor em início de carreira, o qual denominamos de Joaquim. A entrevista reflexiva consiste em uma entrevista semi-dirigida, cujo direcionamento está baseado na fala do sujeito entrevistado. A entrevista reflexiva foi realizada na forma de vídeo gravação.

Em face da natureza do objetivo da investigação, o procedimento analítico que adotamos foi a proposta de Núcleos de Significação por permitir ao pesquisador a apreensão e o desvelamento da subjetividade do professor analisado, isto é, seus modos de pensar, sentir e agir ao discutir as zonas de significado e sentido que estão sendo produzidas (AGUIAR; OZELLA, 2013). Essa escolha justifica-se, também, pelo fato desse procedimento, de uso específico em investigações de natureza qualitativa, por priorizar análise mais aprofundada dos dados produzidos, bem como das significações constituídas pelo professor investigado. 


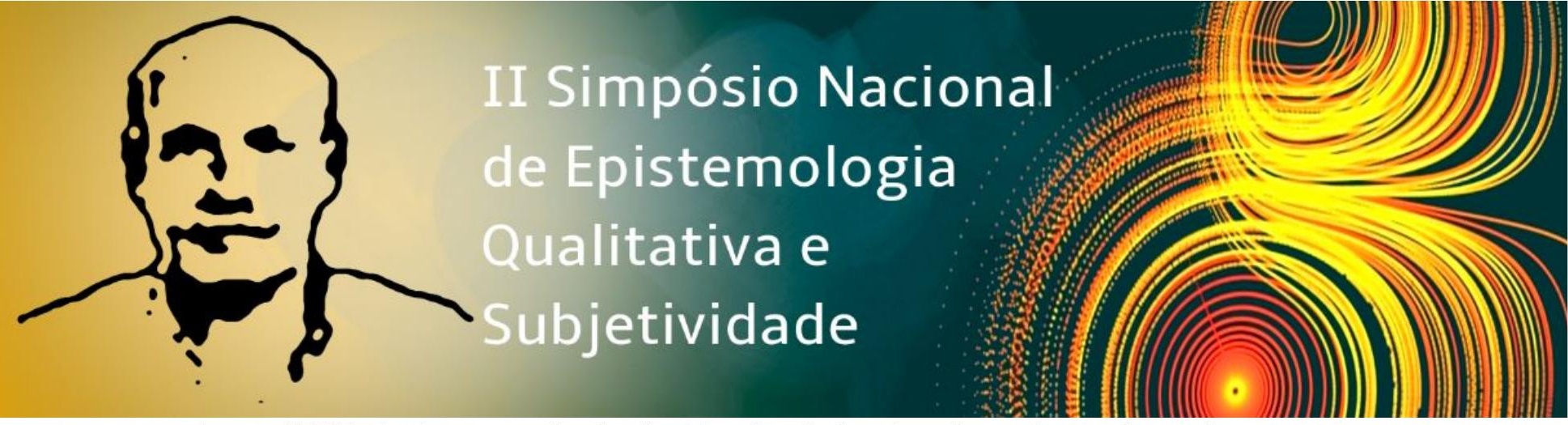

A possibilidade de o pesquisador ir além dos dados descritos, chegando, assim, as zonas de sentido, foi outro aspecto importante no uso desse procedimento de pesquisa.

Para Aguiar e Ozella (2013, p. 310)

na perspectiva de melhor compreender o sujeito, os significados constituem o ponto de partida: sabe-se que eles contêm mais do que aparentam e por meio de um trabalho de análise e interpretação, pode-se caminhar para as zonas mais instáveis, fluidas e profundas, ou seja, para as zonas de sentido.

No caso da nossa investigação, ao empregar os Núcleos de Significação, conseguimos apreender algumas zonas de sentido que constituem e explicam o trabalho docente do professor investigado. Nesse processo de análise, realizamos os seguintes procedimentos metodológicos: a) leituras sucessivas do tema "formação de professores", "indução profissional" e "subjetividade docente"; b) constituição dos núcleos de significação, a saber: 1. A pessoa do professor; 2. Por que se tornou professor; 3. Formação profissional inicial e docência; 4. As primeiras experiências como professor; 5. Desenvolvimento profissional docente.; c) entrevista semiestruturada; d) análise dos dados e escrita do estudo de caso.

\section{Resultados e análises}

\section{Coleta dos dados}

De acordo com Feiman-Nemser (2001 apud NONO, 2011, p. 19), os primeiros anos de profissão representam um período intenso de aprendizagens e influenciam não apenas a permanência do professor na carreira, mas também o tipo de professor que o iniciante virá a ser.

Garcia (1999, p. 105) descreve os primeiros anos de iniciação na carreira docente como

o período de tempo que compreende os primeiros anos, nos quais os professores precisam realizar a transição de estudantes a docentes. É uma etapa de tensões e aprendizagens intensivas em contextos geralmente desconhecidos, durante a qual os professores principiantes devem adquirir conhecimento profissional, além de conseguir manter certo equilíbrio pessoal. 


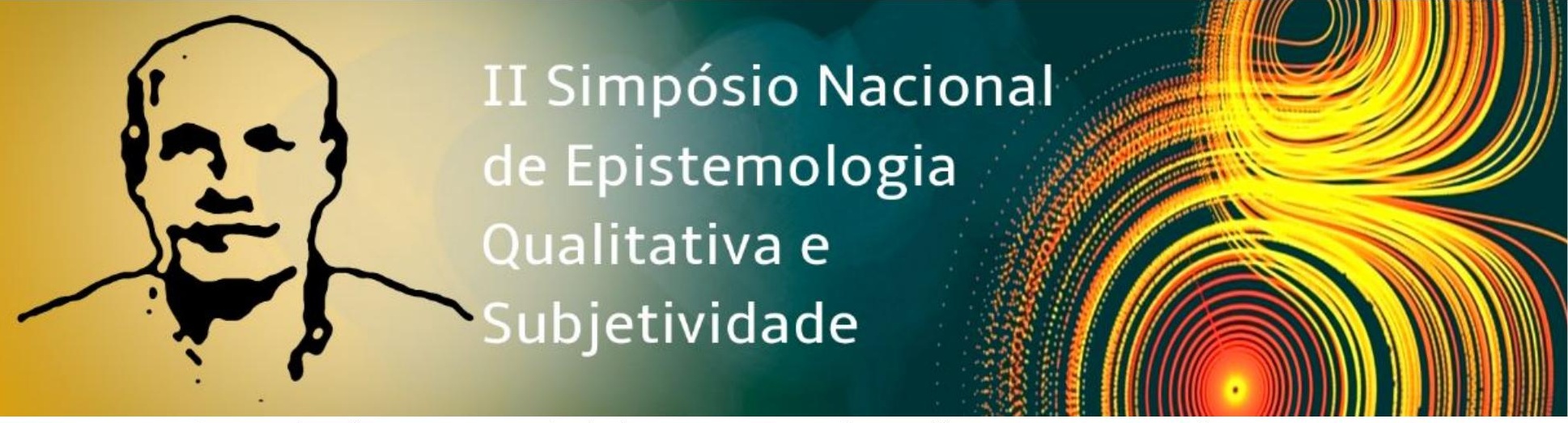

Pensando nisso, para servir de base a este estudo, realizamos uma entrevista com um professor em início de carreira, ou seja, enquadrado nos primeiros anos de docência e situado dentro dessa caracterização traçada nas pesquisas que tratam sobre os primeiros anos na profissão docente.

O professor convidado para a entrevista que deu base ao estudo de caso, denominado aqui de Joaquim, formou-se em Bacharelado em Engenharia Civil e após a conclusão do curso foi trabalhar na área da engenharia civil como responsável por projetos e execuções de obras públicas. Após ser convidado com frequência para ministrar workshops para alunos de Ensino Médio a fim de apresentá-los o curso de Engenharia Civil, teve despertados os primeiros desejos de tornar-se docente. Ministrou, então, uma disciplina no curso de Engenharia Civil, por um semestre letivo, em uma instituição de ensino superior privada e depois passou a ser professor do curso de Técnico em Edificações, Educação Profissional, no Serviço Nacional de Aprendizagem Industrial - SENAI.

A entrevista foi realizada via gravação em vídeo e depois transcrita fidedignamente e transformada em narrativa após o entrevistado assinar o Termo de Consentimento Livre e Esclarecido - TCLE. A entrevista foi semiestruturada e organizada em núcleos de significação a fim de abranger a totalidade dos significados que um processo de iniciação à docência possibilita, a saber: 1. A pessoa do professor; 2. Por que se tornou professor; 3. Formação profissional inicial e docência; 4. As primeiras experiências como professor; 5. Desenvolvimento profissional docente.

Análise dos dados

É no início da carreira que estruturação do saber experiencial é mais forte e importante, estando ligada à experiência de trabalho. O início da carreira é acompanhado, também, de uma fase crítica, pois é a partir das certezas e dos condicionantes da experiência prática que os professores julgam sua formação universitária anterior.

Os primeiros anos da profisssão "[...] representam um período intenso de aprendizagens e influenciam não apenas a permanência do professor na carreira, mas também o tipo de professor que o iniciante virá a ser" (NONO, 2011, p. 19). 


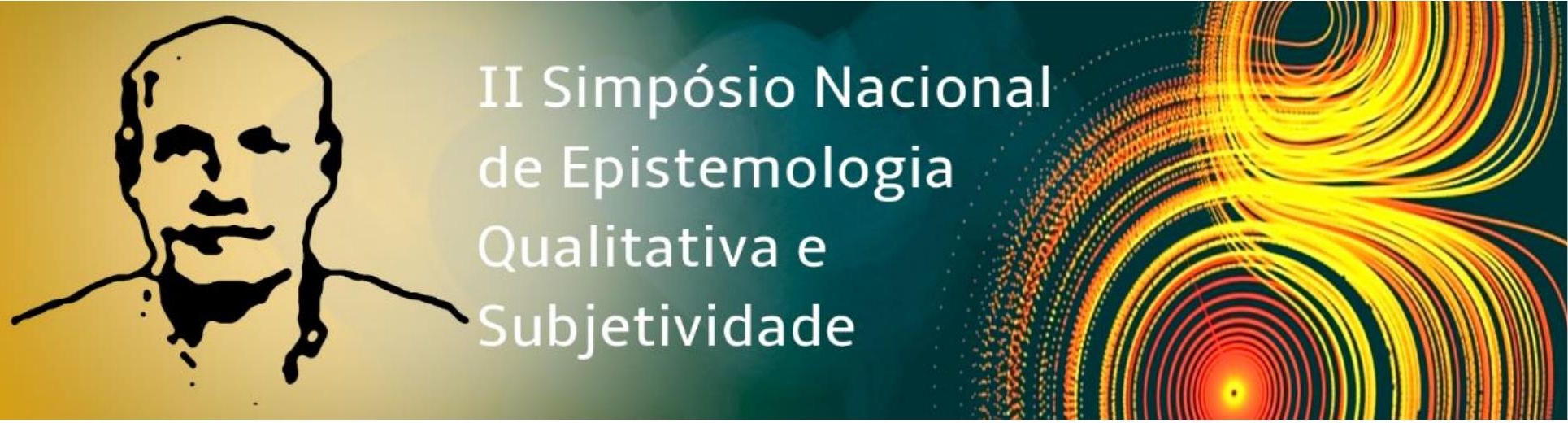

Eu não tive na minha formação como profissional nenhuma formação de como eu ia dar aula [...] eu tive que me inspirar naqueles professores que eu tive para poder produzir alguma coisa similar com que eles produziam (Joaquim, 2019).

Essa fase crítica e de distanciamento dos conhecimentos acadêmicos anteriores provoca também um reajuste nas expectativas e nas percepções anteriores. É necessário rever a concepção inicial de "professor ideal” (TARDIF, 2002). Com o passar do tempo, os professores aprendem a compreender melhor os alunos, suas necessidades, suas carências, etc. Com efeito, o "choque de realidade" força a questionar essa visão idealista partilhada pelos professores novatos, visão essa que, por uma questão de sobrevivência, deve ser apagada:

O decorrer da formação do engenheiro civil é muita prático [...] a gente pega muita disciplina técnica [...] alguns professores queriam formatar a gente como matemático ou físico. [...] eu acho que o principal desafio para mim é que desde a infância sempre fui muito introvertido e quando eu comecei a ministrar as disciplinas e chegar na universidade, ver aqueles alunos todos efusivos, todos interessados pensando que a gente vai chegar já dando aquela aula-show, a gente fica meio espantado [...] a gente entra em choque mesmo [...] (Joaquim, 2019).

Isso corrobora com o entendimento de que no processo identitário deve, necessariamente, considerar sua trajetória, seu contexto de vida e assim resgatar o seu imaginário (condição alienante) para ir para o registro simbólico (condição desejante).

Nesse sentido, Nono (2011, p. 22) também alerta que "[...] o confronto com a realidade força os professores novatos a questionar a visão idealista que possuem sobre a profissão docente", ou seja, mutas vezes distanciados dos conhecimentos acadêmicos e totalmente focados no exercício da profissão, os professores iniciantes passam a reajustar suas expectativas e percepções anteriores, vindo a situar melhor os alunos, suas necessidades, carências e etc.

Além do mais, na educação básica você também tem que lidar com a disciplina, a bagunça em sala de aula, alunos que não querem assistir aula, tenho muitos problemas com isso. E eu sinto um pouco de falta de apoio da gestão, sinto falhas no apoio da coordenação e da direção quanto às conduções da sala de aula, principalmente pra mim, um professor praticamente sem experiência (Joaquim, 2019).

Mesmo sentindo esse "choque de realidade" ao se deparar com uma situação totalmente diferenciada do que o ensino objetivou durante a formação inicial, os professores iniciantes 


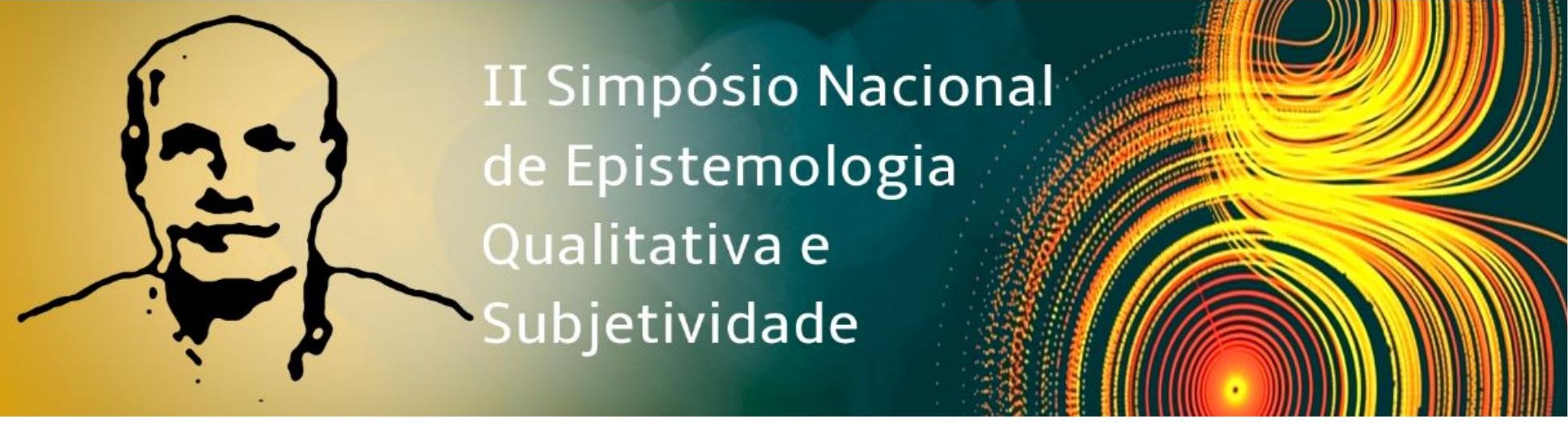

possuem em comum o interesse em se esforçar para que seus alunos aprendam. Para isso, não obstante inovam, mudam as metodologias, "[...] possuem e mobilizam um conjunto de conhecimentos na tentativa de garantir que seus alunos aprendam" (NONO, 2011, p. 46).

[...] o método do jeito que eu aprendi, principalmente com esse público que eu tô lidando agora, adolescentes, eles são muito rápidos, é completamente diferente do público da minha geração. Eles exigem demais, é um negócio completamente diferente e eu tô tendo que, a duro custo, utilizar da tecnologia que eu tenho hoje para adequar esse meu público (Joaquim, 2019).

O domínio progressivo do trabalho provoca uma abertura em relação à construção de suas próprias aprendizagens, de suas próprias experiências, situação essa ligada a uma maior segurança e ao sentimento de estar dominando bem suas funções.

Para Nono (2011, p. 52)

o raciocínio pedagógico se inicia com a compreensão de ideias e conceitos de um mesmo conteúdo e conteúdos relacionados, com o entendimento das estruturas e princípios que fundamentam as disciplinas e a construção dos conteúdos que a constituem.

Percebemos isso ao constatar o que diz o entrevistado sobre a execução do fazerpedagógico:

[...] é um planejamento que você tem que fazer, é uma dinâmica que você tem que pensar diferente, é aquele aluno que você tem que entender a dificuldade que ele tá passando na sua casa para poder tá ali, entendeu, então é toda uma situação, todo um porém além de que aquilo que a gente só vê ali: professor na sala de aula com quadro e algum tipo de material (Joaquim, 2019).

É natural que, com o passar do tempo, conforme evolui na carreira docente e enfrenta os acontecimentos que marcam sua trajetória nas escolas onde atua e nas classes em que leciona, grande parte dos iniciantes desenvolve maior segurança e domínio sobre seu trabalho cotidiano, passando a sentir-se mais confortável diante das exigências da profissão e da tarefa de ensinar (NONO, 2011). 


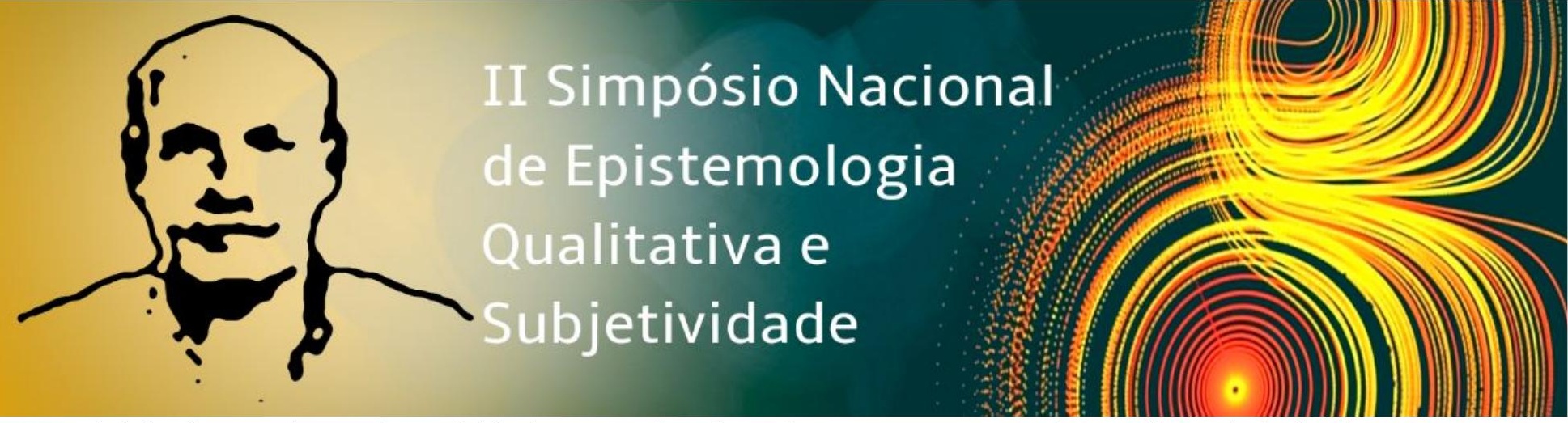

inicio de carreira, tenha sofrido intervenções do meio no seu processo de escolha e de indução profissional de modo a potencializar a docência e diminuir suas frustrações e anseios.

As relações de intervenções deram-se de maneira leve, sem estarem apoiadas em ações de acompanhamento e de suporte ao professor em início de carreira docente como pode-se perceber nas falas do Joaquim durante a entrevista realizada.

A análise da iniciação na carreira docente do professor entrevistado permitiu perceber que essas relações com as socializações do saber pedagógico estão fragilizadas, no caso em análise, não possibilitando, assim, uma evolução rápida e qualitativa no processo de indução profissional do Joaquim.

No pensamento de Tardif, Lessard e Lahaye (1991, p. 231) “é, através das relações com os pares e, portanto, através do confronto entre saberes produzidos pela experiência coletiva dos professores, que os saberes da experiência adquirem uma certa objetividade". As certezas subjetivas devem, então, se sistematizar a fim de serem traduzidas em um discurso da experiência capaz de informar ou de formar outros docentes e de responder a seus problemas "[...] de modo que aprender a ensinar seja realizado através de um processo em que o conhecimento prático e o conhecimento teórico possam integrar-se num currículo orientado para a ação"(MARCELO GARCIA, 1999, p. 29).

O professor iniciante vê-se mergulhado em um contexto de dúvidas e tensões, e ainda precisa adquirir um conhecimento e competências profissional em um curto espaço de tempo. Quando esse professor iniciante vem de uma formação inicial em nível de licenciatura algumas situações de aprendizagem já lhe são mais comuns, no entanto, quando este vem de curso de bacharelado, que é o caso do entrevistado para esta pesquisa, as dúvidas e tensões são mais aparentes e permanentes.

A partir do resultado da pesquisa e concordando com Lima (2006), entendemos que o início da docência é uma fase delicada na constituição do ser professor. Será, então, que podemos afirmar que as marcas da identidade, de subjetividade e do estilo caracterizam a carreira docente?

\section{Referências}




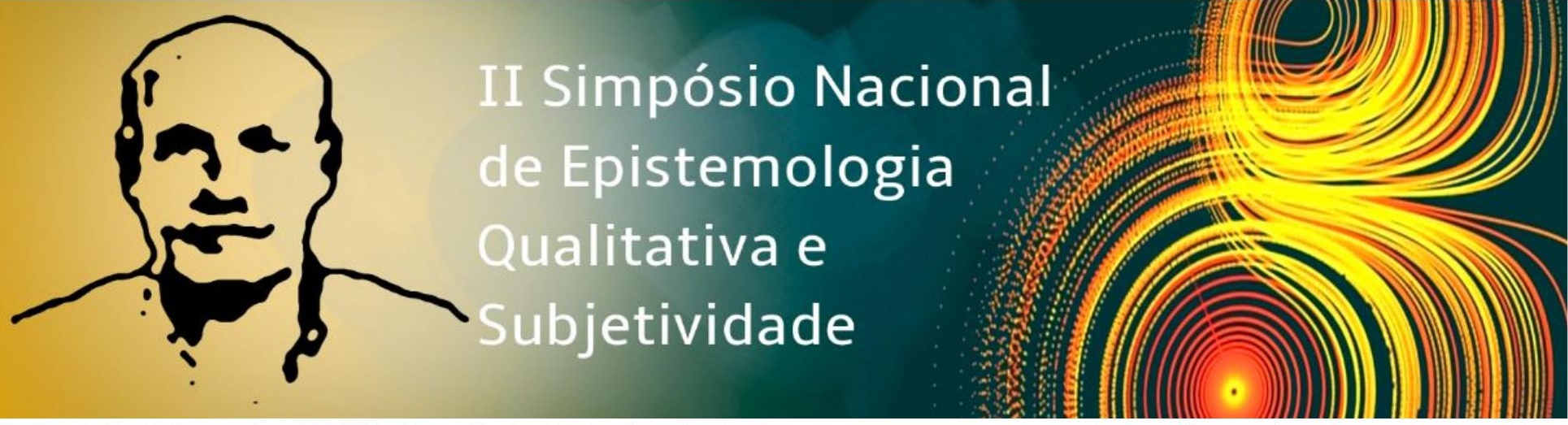

TARFID, M.; LESSARD, C.; LAHAYE, L. Os professores face ao saber: esboço de uma problemática do saber docente. Teoria \& Educação, n. 4, Porto Alegre: Pannonica, 1991.

VYGOTSKY, L. S. A formação social da mente. São Paulo: Martins Fontes, 1984. 